\title{
The bisphosphonate zoledronic acid impairs membrane localisation and induces cytochrome $c$ release in breast cancer cells
}

\author{
SG Senaratne', JL Mansi' and KW Colston*,1 \\ 'Department of Oncology, Gastroenterology, Endocrinology and Metabolism, St George's Hospital Medical School, Cranmer Terrace, London SWI7 ORE, UK
}

Bisphosphonates are well established in the management of cancer-induced bone disease. Recent studies have indicated that these compounds have direct inhibitory effects on cultured human breast cancer cells. Nitrogen-containing bisphosphonates including zoledronic acid have been shown to induce apoptosis associated with PARP cleavage and DNA fragmentation. The aim of this study was to identify the signalling pathways involved. Forced expression of the anti-apoptotic protein bcl-2 attenuated bisphosphonate-induced loss of cell viability and induction of DNA fragmentation in MDA-MB-23I cells. Zoledronic acid-mediated apoptosis was associated with a time and dose-related release of mitochondrial cytochrome $c$ into the cytosol in two cell lines. Rescue of cells by preincubation with a caspase-3 selective inhibitor and demonstration of procaspase- 3 cleavage products by immunoblotting suggests that at least one of the caspases activated in response to zoledronic acid treatment is caspase-3. In both MDA-MB-23I and MCF-7 breast cancer cells, zoledronic acid impaired membrane localisation of Ras indicating reduced prenylation of this protein. These observations demonstrate that zoledronic acidmediated apoptosis is associated with cytochrome $\mathrm{c}$ release and consequent caspase activation. This process may be initiated by inhibition of the enzymes in the mevalonate pathway leading to impaired prenylation of key intracellular proteins including Ras.

British Journal of Cancer (2002) 86, I479- |486. DOI: 10.1038/sj/bjc/6600297 www.bjcancer.com

(c) 2002 Cancer Research UK

Keywords: bisphosphonates; breast cancer; apoptosis; caspases; Ras; cytochrome c

Breast cancer commonly metastasises to bone: over $80 \%$ of women with advanced breast cancer develop bone metastases which ultimately account significantly for morbidity and mortality. Bisphosphonates (BPs) are potent inhibitors of bone resorption and are effective in the treatment of many metabolic bone diseases. In animal models of metastatic disease, BPs have been shown to slow the development of bone metastases and to reduce tumour burden in bone (Wingen et al, 1986; Yoneda et al, 2000). In patients with advanced breast cancer and bone metastases, BPs reduce the incidence of hypercalcaemia and skeletal morbidity (Ryzen et al, 1985). In addition, a recently reported clinical trial of patients with breast cancer has suggested that the BP clodronate given in the adjuvant setting can reduce the incidence of skeletal metastases with a consequent improvement in survival (Diel et al, 1998). Such observations could indicate that BPs have direct inhibitory effects on breast cancer cells. This suggestion is supported by the demonstration that BPs inhibit breast cancer cell adhesion to bone in vitro (van der Pluijm et al, 1996; Boissier et al, 1997).

We have recently demonstrated that two amino bisphosphonates (N-BPs), pamidronate and zoledronic acid (ZOL), directly inhibit growth and viability of cultured human breast cancer cells. These effects are accompanied by morphological changes, induction of

*Correspondence: K Colston; E-mail: k.colston@sghms.ac.uk Received 23 November 200 I; revised 12 March 2002; accepted 13 March 2002
DNA fragmentation, decreased bcl-2/bax ratio and PARP cleavage indicative of caspase activation (Senaratne et al, 2000). These findings have been confirmed by reports from two other groups that provide evidence for caspase activation in N-BP-induced apoptosis in breast cancer cells (Fromigue et al, 2000; Hiraga et al, 2001). Initiation of the caspase cascade in response to many apoptotic stimuli is a consequence of cytochrome $c$ release from mitochondria into the cytosol (Li et al, 1997; Zou et al, 1997). It has been suggested that bcl-2 prevents the release of cytochrome $c$, thereby inhibiting the activation of caspases (Marzo et al, 1998). One of the aims of the present study was to clarify the involvement of bcl-2 and cytochrome $c$ in caspase activation induced by the $\mathrm{N}$ $\mathrm{BP}, \mathrm{ZOL}$ in breast cancer cells. In this study we show for the first time that treatment of breast cancer cells with ZOL is associated with release of mitochondrial cytochrome $c$ into the cytosol consistent with a decrease in the action of bcl-2. To further support a relationship between bcl-2 and N-BP mediated apoptosis, we now report that forced expression of bcl-2 abrogates ZOL-induced DNA fragmentation which is a consequence of caspase activation in breast cancer cells.

In order to identify further the mechanisms initiating this caspase activation leading to $\mathrm{N}$-BP-induced apoptosis in breast cancer cells, we evaluated the possible role of impaired protein prenylation. Recent pharmacological studies suggest that N-BPs such as pamidronate, alendronate and risedronate act on the enzymes in the mevalonate pathway leading to decreased generation of isoprenoid intermediates required for post-translational prenylation of key cellular proteins. This is the suggested mechan- 
ism by which N-BPs mediate apoptosis in macrophages and myeloma cells (Luckman et al, 1998; Shipman et al, 1998). However, the identity of the proteins that are ineffectively prenylated following N-BP treatment of breast cancer cells is presently unknown. Ras proteins play pivotal roles in the control of normal and transformed cell growth. For functional activity, Ras requires membrane localisation and this is mediated by post-translational modification by the addition of a 15-carbon farnesyl isoprenoid. By inhibiting farnesyl pyrophosphate (FPP) generation, N-BPs might thus impair normal farnesylation of Ras. In this study we present support for this potential mechanism and report for the first time that treatment with ZOL leads to impaired membrane localisation of Ras protein in breast cancer cells that express both wild-type and mutant ras.

\section{METHODS}

\section{Cell lines}

The breast cancer cell lines MDA-MB-231 (provided by Professor RC Coombes, Imperial College, UK), and MCF-7 (Danish Cancer Society, Copenhagen, Denmark), were maintained in Dulbecco's Modified Eagle Medium (DMEM) supplemented with $100 \mathrm{U} \mathrm{ml}^{-1}$ streptomycin and $5 \%$ foetal calf serum (FCS) at a constant temperature of $37^{\circ} \mathrm{C}$ with a humidified atmosphere of $5 \% \mathrm{CO}_{2}$. Cells were routinely tested for mycoplasma contamination. Caspase-3 expressing MCF-7 cells, a kind gift from Professor Alan Porter (The National University of Singapore, Singapore), were maintained as above together with $200 \mu \mathrm{g} \mathrm{ml}{ }^{-1}$ G418 sulphate (Geneticia, Life Technologies, Paisley, UK).

\section{Reagents}

Disodium salt of zoledronic acid ((1-hydroxy-2-imidazol-1-yl-phosphonoethyl) phosphonic acid) was obtained from Novartis Pharmaceuticals Limited (Basle, Switzerland). Cell permeable caspase-3 inhibitor 1 (Ac-Ala-Ala-Val-Ala-Leu-Leu-Pro-Ala-ValLeu-Leu-Ala-Leu-Leu-Ala-pro-Asp-Glu-Val-Asp-CHO) and tumour necrosis factor alpha (TNF- $\alpha$ ) were obtained from Calbiochem, $\mathrm{CN}$ Biosciences (Nottingham, UK). Farnesol (3,7,11-Trimethyl-2-6,10dodecatrien-1-ol, mixed isomers), and trans, trans-geranylgeraniol (all trans-3,7,11,15-tetramethyl-2,6,10,14-hexadecatetraenyl pyrophosphate) were obtained from Sigma-Aldrich Company Ltd (Poole, Dorset, UK). The pUSEamp $(+)$ plasmid containing wild-type mouse bcl-2 under the control of the cytomegalovirus promoter was obtained from Upstate Biotechnology (Lake Placid, NY, USA). A control vector without the insert was obtained from the same source.

\section{Measurement of cell viability}

Cell viability was determined by 3-(4,5-dimethylthiazol-2-yl)-5-(3carboxymethoxyphenyl)-2-(4-sulfophenyl)-2H-tetrazolium (MTS) dye reduction assay measuring mitochondrial respiratory function (Cory et al, 1991). Breast cancer cells $\left(2 \times 10^{3}\right.$ per well) were plated into 96-well plates and treated with reagents or vehicle. At the end of the treatment period, MTS dye $(2 \mathrm{mg}$ per $20 \mu \mathrm{l}$ per well) was added to the cell culture medium for $2 \mathrm{~h}$. Absorbance was determined in a Titertek plate reader at $492 \mathrm{~nm}$.

\section{Immunoblotting}

Breast cancer cells were harvested by scraping. Whole cell lysates were prepared by washing the cells in ice cold phosphate buffered saline (PBS) and resuspending in $100 \mu \mathrm{l}$ of lysis buffer $(20 \mathrm{~mm}$ Tris, $40 \mathrm{~mm}$ sodium phosphate, $50 \mathrm{~mm}$ sodium fluoride, $5 \mathrm{~mm}$ magnesium chloride, $10 \mathrm{~mm}$ ethylene glycol-bis(b-aminoethyl ether) $\mathrm{N}, \mathrm{N}, \mathrm{N}^{\prime}, \mathrm{N}^{\prime}$-tetraacetic acid (EGTA), $0.5 \%$ sodium deoxycholate, $1 \%$ Triton $\mathrm{X}-100,0.1 \%$ SDS, $40 \mathrm{mg} \mathrm{ml}^{-1}$ leupeptin,
$100 \mathrm{mg} \mathrm{ml}^{-1}$ aprotinin, $20 \mathrm{mg} \mathrm{ml}^{-1}$ PMSF in Dimethyl sulphoxide (DMSO) and $50 \mathrm{~mm}$ sodium orthovanadate) for $30 \mathrm{~min}$ on ice. Equivalent protein extracts $(28 \mu \mathrm{g})$ from each sample were electrophoresed on $16 \%$ SDS-polyacralamide gels and proteins were immobilised by transfer onto nitrocellulose membranes. Membranes were immunoprobed with $5 \mu \mathrm{lml}^{-1}$ equivalent of rabbit polyclonal antibodies against $\beta$ actin (Sigma-Aldrich Company LTD, UK) and caspase-3 (Santa Cruz, Heidelberg, Germany) followed by a horseradish peroxidase-conjugated secondary antibody to rabbit immunoglobulins (Amersham International, UK). Specific bands were visualised by enhanced chemiluminescence (ECL, Amersham International, UK).

To identify changes in membrane localisation of Ras, breast cancer cells were treated with N-BPs or vehicle for 3 days and harvested by scraping. Cells were disrupted by homogenisation followed by five passes through a 25 gauge needle. Cytosolic and membrane fractions were separated by centrifugation at 43000 r.p.m. for $25 \mathrm{~min}$ as previously described (Mumby et al, 1990). After solubilising in $0.01 \%$ SDS, the soluble fractions were concentrated using Micron 10 microconcentrators (Vivascience, Sartorius group, Goettingen, Germany). Equivalent protein extracts $(10 \mu \mathrm{g})$ of cytosol and membrane fraction from each sample were electrophoresed on $12 \%$ SDS - PAGE mini gels. A mouse monoclonal primary antibody generated against Ha-Ras protein $\mathrm{p} 21$, which recognises wild-type and mutant Ras forms (Transduction Laboratories, CA, USA) was used to immunoprobe membranes. Proteins were detected using a horseradish peroxidase-conjugated secondary antibody to mouse immunoglobulins (Amersham International, UK). Bands were visualised as described above. An equivalent amount of total protein was loaded on to a separate mini gel consisting only of SDS - PAGE stacking gel. After electrophoresing for $30 \mathrm{~min}$, depending on the contrast of the bands, gels were either scanned fresh or bands were scanned after drying the gel using a gel dryer.

To identify release of cytochrome $c$ to the cytosol from the mitochondria, breast cancer cells were treated with ZOL or vehicle for 3 days and harvested on specified days by scraping. After washing the cells in ice cold PBS, they were resuspended in $500 \mu \mathrm{l}$ of mitochondrial buffer $(250 \mathrm{~mm}$ mannitol, $5 \mathrm{~mm}$ potassium dihydrogen orthophosphate, $10 \mathrm{mM}$ ethylenediaminetetraacetic acid (EDTA), $5 \mathrm{~mm}$ 3-(N-Morpholino) propanesulphonic acid (MOPS)). Cell cytosol fraction was separated from the mitochondrial fraction by centrifugation at 13000 r.p.m. for $15 \mathrm{~min}$ at $4{ }^{\circ} \mathrm{C}$ and, after resuspending in the same supernatant, centrifuged again at 13000 r.p.m. for a further $15 \mathrm{~min}$ as previously described (Slee et al, 2000). The soluble (cytosol) fractions were concentrated using Micron 10 microconcentrators. Aliquots of cytosol fractions with equivalent protein content $(15 \mu \mathrm{g})$ from each sample were electrophoresed on 15\% SDS - PAGE mini gels. Mouse monoclonal primary antibodies generated against cytochrome $c$ (BD PharMingen, Becton Dickinson, NJ, USA) or $\beta$ actin was used to immunoprobe membranes. Proteins were detected using a horseradish peroxidase-conjugated secondary antibody to mouse immunoglobulins. Bands were visualised as described above.

\section{DNA fragmentation assay}

Breast cancer cells were incubated with $\left[{ }^{3} \mathrm{H}\right.$-methyl]-thymidine $\left(0.1 \mu \mathrm{Ci} \mathrm{ml}{ }^{-1}\right)$ for $9-16 \mathrm{~h}$ to label DNA and then washed before exposure to the indicated treatment. Cells were lysed with lysis buffer and fragmented double stranded DNA was separated from chromosome-length, unfragmented DNA followed by trichloroacetic acid (TCA) precipitation (Duke and Cohen, 1992).

\section{Stable transfections}

MDA-MB-231 cells were transfected with pUSEamp(+) bcl-2 plasmid or a control plasmid without insert, using SuperFectTM 
A

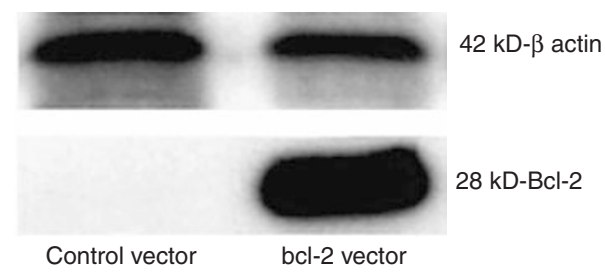

B
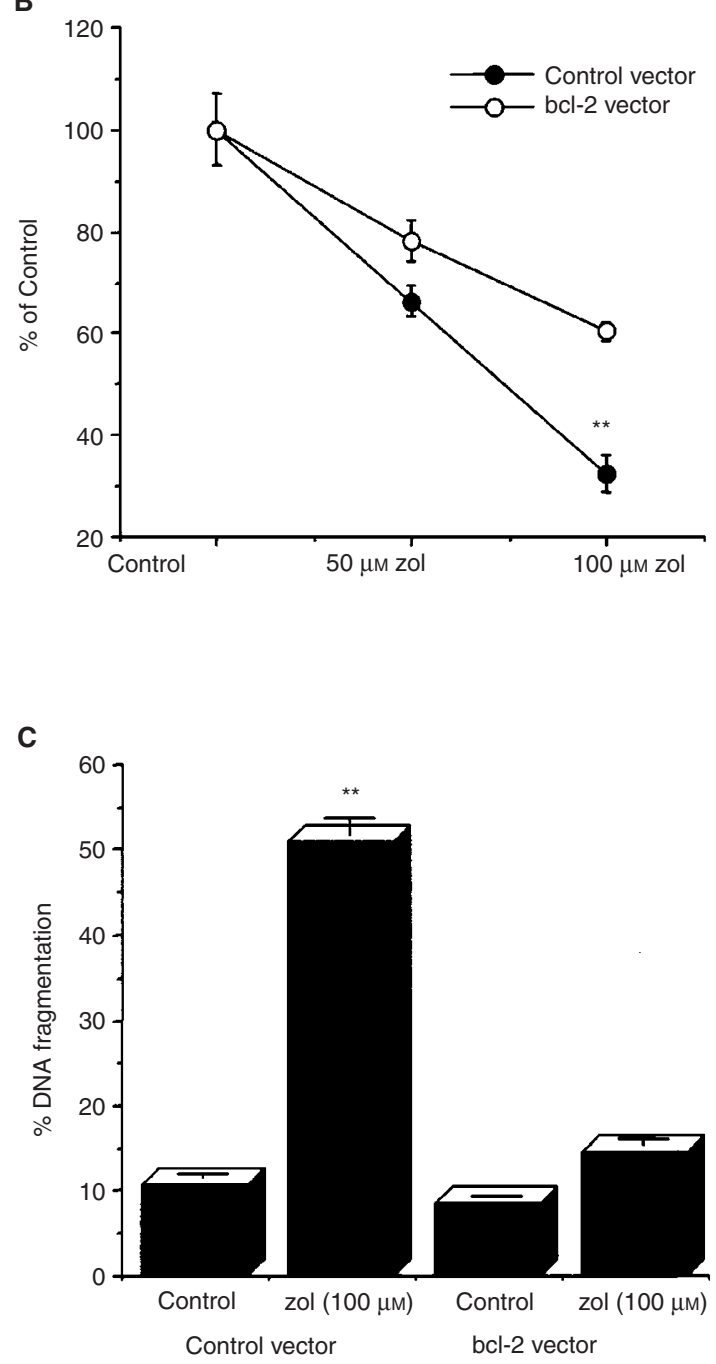

Figure I (A) Immunoblotting of bcl-2 protein in whole cell extracts of MDA-MB-23I clone-I transfected with pUSEamp (+) plasmid containing wild-type mouse bcl-2 and a clone transfected with control vector. Levels of bcl-2 expression in transfected and control clones were compared relative to $\beta$ actin protein. (B) Overexpression of bcl- 2 suppresses $Z O L$ effects on breast cancer cells. Both control vector and bcl-2 overexpressing MDAMB-23I cells (clone I) were incubated with 0,50 and 100 $\mu \mathrm{M}$ ZOL for 3 days and cell viability was quantitated by MTS dye reduction assay. Clone I was shown to be significantly less sensitive to ZOL induced reduction in cell viability than cells transfected with control vector. Results are shown as mean \pm s.d. Significance was $* * * 0.000$ I compared to bcl-2-transfected cells treated with $100 \mu \mathrm{M} Z \mathrm{ZOL}$. $(\mathbf{C})$ The induction of DNA fragmentation by $Z O L$ on MDA-MB-23 I cells was significantly inhibited in MDA-MB-23 I clone I, overexpressing bcl-2. Both control vector and clone I cells were treated with $100 \mu \mathrm{M}$ of $Z O L$ for 3 days. Results are shown as mean \pm s.d.. $\mathrm{ZOL}$ treatment significantly increased DNA fragmentation in control clone. $* * P<0.000$ I (In bcl-2 transfected cells I00 $\mu \mathrm{M}$ of ZOL did not significantly increase DNA fragmentation. $P=0.053$ ). transfection reagent (Qiagen Ltd. West Sussex, UK) according to the manufacturers' instructions. Selection of transfected clones was done using culture medium containing $2 \mathrm{mg} \mathrm{ml}^{-1} \mathrm{G} 418$ sulphate. Expression of bcl-2 was assessed by Western blotting on whole cell lysates of selected clones using an antibody recognising murine bcl-2 (DAKO, High Wycombe, UK)

\section{Statistics}

All experiments were performed at least twice and results shown are mean of replicate samples $(n=4)$ from a single experiment. Statistical analysis of the data was carried out using analysis of variance with ANOVA: Schiffe test using Statview 4.0 software package for the Apple Macintosh. Statistical significance is indicated as ${ }^{* *} P<0.0001$ compared to control unless otherwise stated.

\section{RESULTS}

\section{Suppression of ZOL-induced apoptosis by bcl-2}

To elucidate the role of bcl-2 and ZOL-induced apoptosis in breast cancer cells, we determined whether forced expression of bcl-2 was capable of abrogating ZOL-induced loss of cell viability and DNA fragmentation. Transfection of MDA-MB-231 cells with the pUSEamp (+) plasmid containing a wild-type mouse bcl-2 resulted in generation of at least two clones which stably over-expressed bcl-2. Clone 1, which had the highest expression, and a control transfected clone (C1) (Figure 1A), were used in subsequent experiments to assess the role of bcl-2 in ZOL-induced apoptosis. The inhibitory effects of ZOL on MDA-MB-231 cell viability was suppressed by bcl-2 as clone 1 was shown to be significantly less sensitive than cells transfected with control vector (Figure 1B) or parental cells (data not shown). Following treatment with $100 \mu \mathrm{M}$ ZOL for 3 days, loss of cell viability was significantly attenuated in cells over-expressing bcl-2 compared to control-vector transfected cells. Furthermore, in cells transfected with control-vector, $100 \mu \mathrm{M}$ ZOL induced a five-fold increase in DNA fragmentation after 3 days of treatment compared to vehicle treated cultures (Figure 1C). However in cultures over-expressing bcl-2 this increase was less than two-fold compared to respective control.

\section{Cytochrome $c$ release}

The anti-apoptotic members of the bcl-2 family of proteins inhibit mitochondrial cytochrome $c$ release and caspase activation. To examine this aspect of the apoptotic pathway, MDA-MB-231 cells were treated for up to 3 days with $100 \mu \mathrm{M}$ ZOL and MCF-7 cells were treated with 10,50 and $100 \mu \mathrm{M}$ of $\mathrm{ZOL}$ for 3 days, and the appearance of cytochrome $c$ in cytosol fractions was determined by Western blot analysis. Figure $2 \mathrm{~A}$ and $\mathrm{C}$ demonstrates that there is an induction of cytochrome $c$ release into the cytosol with increasing time and concentration respectively of treatment with ZOL. To our knowledge, this is the first demonstration that mitochondrial cytochrome $c$ release has been shown in association with N-BP mediated apoptosis in any cell line.

\section{ZOL treatment induces activation of caspase 3}

On activation pro-caspase-3 $(34 \mathrm{kD})$ is cleaved into two fragments of 20 and $11 \mathrm{kD}$. To investigate the relationship of ZOL induced cytochrome $c$ release on effects on caspase- 3 activation, MDAMB-231 cells were incubated for 3 days with ZOL $(100 \mu \mathrm{M})$, cell lysates were prepared and immunoblotting was carried out with an antibody recognising pro-caspase- 3 and its cleavage products. Cleavage consistent with caspase- 3 activation was observed in ZOL treated cells, but only the $34 \mathrm{kD}$ full-length pro-caspase- 3 species was detected in control (vehicle treated) cultures (Figure $3 \mathrm{~A})$. Both pro-caspase- 3 and its cleaved products were absent from 


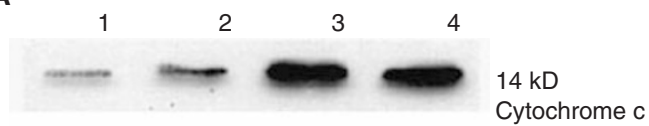

目且目目

B

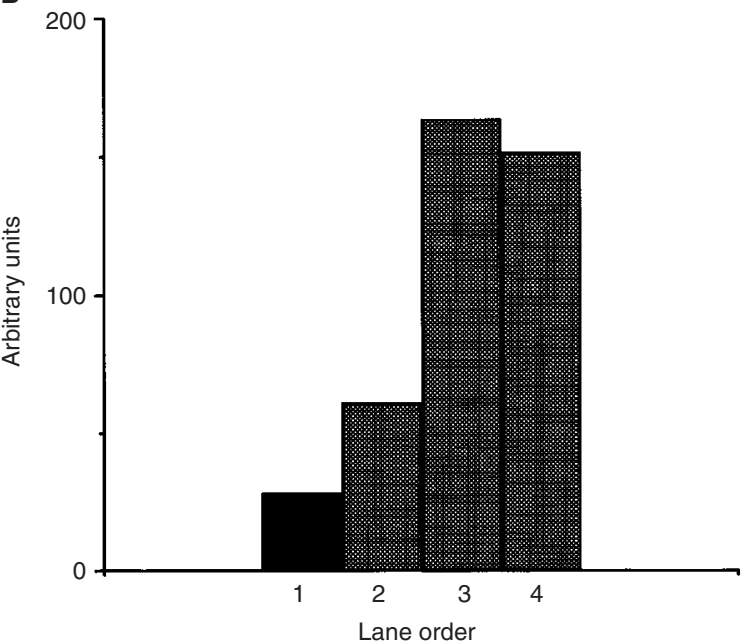

C
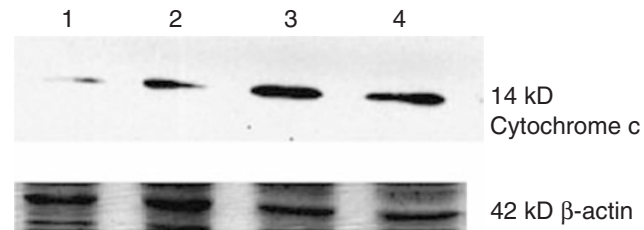

Figure 2 (A) MDA-MB-23I cells were incubated in the presence of $100 \mu \mathrm{M} Z \mathrm{OL}$ and cell extracts were prepared on specified days. Extracts were twice centrifuged at 13000 r.p.m. for 15 min and the post-mitochondrial supernatant (cytosol) was concentrated as described in Materials and Methods. Cytochrome c levels in samples having equivalent protein contents (I5 $\mu \mathrm{g})$ were determined by Western analysis. Lane order: I, control cultures day 3; 2, ZOL treated, day 1; 3, ZOL treated, day 2; and 4, ZOL treated, day 3. (B) Corresponding densitometric analysis of cytochrome $c$ levels in cytosol for each day of treatment. (C) MCF-7 cells were incubated in the presence of I0, 50 and $100 \mu \mathrm{M} Z \mathrm{OL}$ and cell extracts were prepared after 3 days of above treatments. Cytosol fractions were prepared as described above and the cytochrome c levels in samples having equivalent protein contents $(20 \mu \mathrm{g})$ were determined using Western analysis. Lane order: I, control cultures; 2, I0 $1 \mathrm{M}$ ZOL; 3, $50 \mu \mathrm{M} Z \mathrm{OL}$; and 4, I00 $\mu \mathrm{M}$ ZOL. (D) Corresponding densitometric analysis of cytochrome $c$ levels in cytosol for each treatment.

extracts of MCF-7 cells either untreated (not shown) or treated with TNF- $\alpha 12 \mathrm{ng} \mathrm{ml}^{-1}$ for $24 \mathrm{~h}$ (Figure 3A). MCF-7 cells do not express caspase-3, but are still induced to undergo apoptosis by a number of agents (Kurokawa et al, 1999) suggesting that cell death could be associated with activation of another, as yet unidentified caspase in these cells. To determine whether N-BPs can modulate caspase- 3 in these cells, we assessed effects of ZOL on a transfected clone of MCF-7 cells stably expressing caspase-3. These cells also underwent apoptosis with ZOL treatment as assessed by loss of cell viability (data not shown) and cleavage of pro-caspase- 3 consistent with activation was observed after treatment with ZOL for 3 days (Figure 3B).

To further confirm the role of caspase- 3 activation in ZOLmediated apoptosis, MDA-MB-231 cells were preincubated with a caspase-3-selective inhibitor $(0.5 \mu \mathrm{M}) 3 \mathrm{~h}$ prior to addition of ZOL $(35 \mu \mathrm{M})$. After $24 \mathrm{~h}$ incubation, medium was removed and replenished with fresh medium containing only the caspase- 3 inhibitor or DMSO vehicle. Results showed that the caspase-3-selective inhibitor provided full protection against cell death induced by this $\mathrm{N}$-BP (Figure 3C), thus implicating activation of caspase-3 in its mechanism of action.

\section{Effects on membrane localisation of Ras}

The initiating signal for N-BP mediated apoptosis in breast cancer cells is presently unknown. However, it has been suggested previously that N-BP-induced apoptosis in other cell types may be associated with impaired prenylation of key cellular proteins. Prenylation of Ras is required for its normal membrane localisation and function (Rowinsky et al, 1999).

In order to determine if ZOL treatment affects Ras membrane localisation, MDA-MB-231 cells, which have mutated K-ras (Gilhooly and Rose, 1999), were incubated for 3 days with $100 \mu \mathrm{M}$ ZOL and Ras protein levels in cytosol and membrane fractions were determined by immunoblotting. Figure $4 \mathrm{~A}$ demonstrates that in control cultures Ras is predominantly associated with the cell membrane fraction. However, in cultures treated with ZOL for 3 days, Ras is predominantly found in the cytosol fraction and the amount of Ras protein associated with the cell membrane is greatly reduced. These results lend further support to the suggestion that treatment of MDA-MB-231 cells with ZOL inhibits generation of FPP leading to decreased prenylation of Ras. Similar failure of Ras membrane localisation was seen with MCF-7 cells (wild-type ras) treated with ZOL (Figure 4B) while co-treatment with mixed isomers of farnesol $(\mathrm{FOH})$ attenuated this effect.

\section{Farnesol (mixed isomers) provides protection against ZOL-induced loss of cell viability}

In order to assess the efficacy of various isoprenoids to attenuate ZOL-mediated apoptosis, we determined effects of co-treatment with farnesol (FOH mixed isomers) and all trans geranylgeraniol 
A

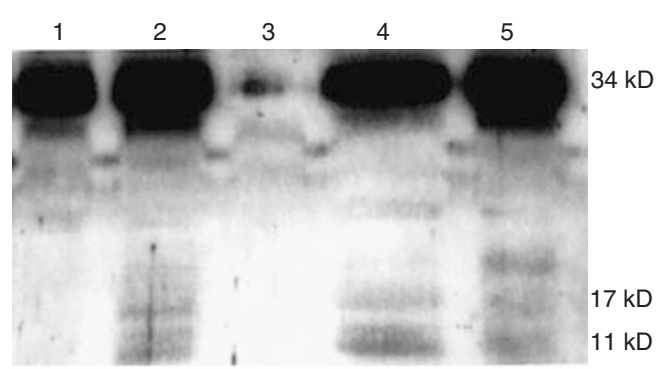

B

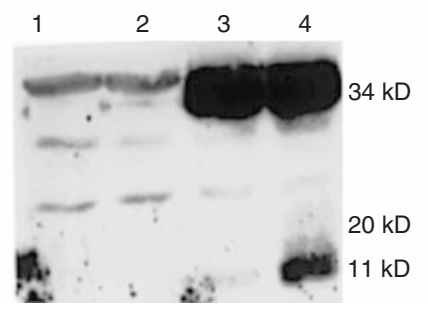

C

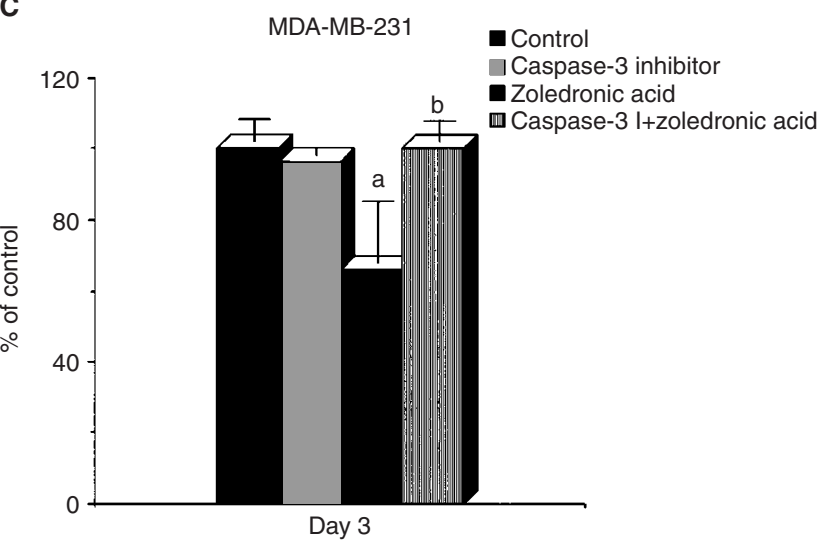

Figure 3 (A) Identification of caspase-3 activity in breast cancer cells. MDA-MB-23I cells were incubated in the presence of $100 \mu \mathrm{M} Z O L$ for 3 days before cell extracts were prepared and Western blot analysis carried out. Two prominent cleaved products of pro-caspase-3 (indicating caspase activation) were seen at 20 and II kD. Lane order: I, MDA-MB-23 I cells treated with vehicle alone: 2 , MDA-MB-23। treated with taxotere $10 \mathrm{nM}$ for 2 days as a positive control; 3, MCF-7 treated with TNF- $\alpha 20 \mathrm{ng} \mathrm{ml}-1$ for 2 days, as a negative control; 4, MDA-MB-23I treated with pamidronate $100 \mu \mathrm{M}$ and 5, MDA-MB-23I treated with ZOL $100 \mu \mathrm{M}$. (B) Identification of caspase-3 activation by ZOL in MCF-7 cells with forced expression of caspase-3. Both control vector and caspase-3 expressing MCF-7 cells were incubated with $100 \mu \mathrm{M} Z O L$ for 3 days before cell extracts were prepared and Western blot analysis carried out. Lane order: I, Control vector MCF-7 treated with vehicle alone; 2, Control vector MCF-7 treated with ZOL; 3 , Caspase-3 expressing MCF-7 treated with vehicle alone and 4, caspase-3 expressing MCF-7 treated with ZOL. (C) Attenuation of ZOL effects by a caspase-3-selective inhibitor. MDA-MB-23I cells were treated with the caspase- 3 inhibitor $(0.5 \mu \mathrm{M}) 3 \mathrm{~h}$ prior to addition of $35 \mu \mathrm{M}$ of $\mathrm{ZOL}$ for $24 \mathrm{~h}$. Medium was then replaced with medium containing either the caspase-3 inhibitor or vehicle (DMSO) alone. On day 3 cell viability was quantitated using MTS dye reduction assay. Results are shown as mean \pm s.d. Significance levels were a $P<0.0005$ vs untreated cells, ${ }^{b} P<0.0005$ vs ZOL treated cells.

(GGOH) on ZOL-induced loss of cell viability. MDA-MB-231 cells were treated with $40 \mu \mathrm{M}$ of each isoprenoid for $3 \mathrm{~h}$ prior to addition of ZOL. After $24 \mathrm{~h}$ co-treatment, media were removed and replenished with fresh media containing isoprenoid or ethanol vehicle only for a further 2 days. At the end of the treatment
A
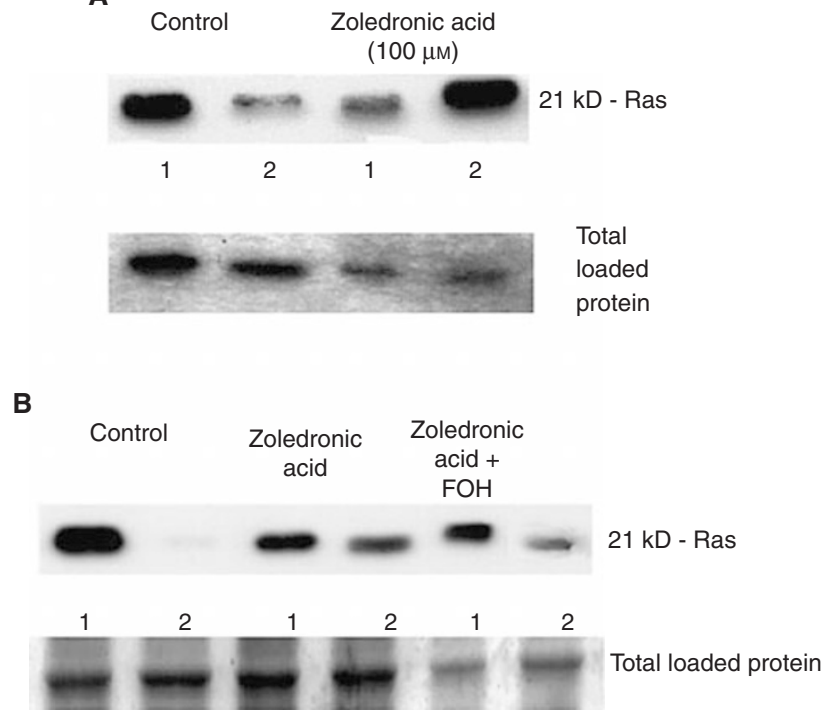

Figure 4 (A) Identification of $Z O L$ induced reduction in active Ras (membrane bound) in MDA-MB-23I cells. MDA-MB-23I cells were treated with $100 \mu \mathrm{M} Z \mathrm{OL}$ for 3 days. Level of expression of Ras protein in cytosol and membrane fractions was determined by Western analysis and equivalence of loading was determined by total protein staining as described in Materials and Methods. Lane order: I, membrane fraction; 2, cytosol fraction. (B) MCF-7 cells were treated with $40 \mu \mathrm{M}$ of FOH (mixed isomers) $3 \mathrm{~h}$ before addition of $50 \mu \mathrm{M} Z \mathrm{OL}$ for $24 \mathrm{~h}$. Medium was then replaced with fresh medium containing $40 \mu \mathrm{M} \mathrm{FOH}$ (mixed isomers) or vehicle only for a further 2 days. Level of expression of Ras protein in cytosol and membrane fractions following each treatment was determined by Western analysis as described above. Equivalence of loading was determined by total protein staining as described in Materials and Methods. Lane order: I, membrane fraction; 2, cytosol fraction.

period, cell viability was assessed by MTS assay. Co-treatment with FOH (mixed isomers) protected against ZOL-induced apoptosis, restoring viability to approximately $90 \%$ of control cultures. Cotreatment with GGOH provided partial protection, since viability of cultures co-treated with ZOL+GGOH was approximately $70 \%$ of respective controls (Figure 5A,B). This study suggests that impaired protein farnesylation may play a more important role in N-BP mediated apoptosis in breast cancer cells than failure of protein geranylgeranylation.

\section{DISCUSSION}

There is increasing evidence that BPs may have direct inhibitory effects on breast cancer cells. These may be related to decreased cell adhesion since pretreatment of MDA-MB-231 breast cancer cells with BPs (ibandronate, olpandronate, pamidronate and alendronate) prevents attachment and spreading of cells onto bone slices (van der Pluijim et al, 1996; Boissier et al, 1997). Animal studies have demonstrated that pretreatment of nude mice with BPs before inoculation of tumour cells reduces the development of osteolytic lesions (Sasaki et al, 1995). Furthermore, a recent study using an in vitro model of cell invasion has suggested that BPs may inhibit this early event in the formation of bone metastases (Boissier et al, 2000). We have shown that BPs directly induce apoptosis in breast cancer cells and this observation has recently been confirmed by other studies (Fromigue et al, 2000; Hiraga et al, 2001; Jagdev et $a l, 2001)$. Our present analysis of the apoptotic pathways affected by ZOL provides insight into the mechanism by which N-BPs induce cell death in breast cancer cells. The bcl-2 family of proand anti-apoptotic proteins plays an important role in apoptosis 
A

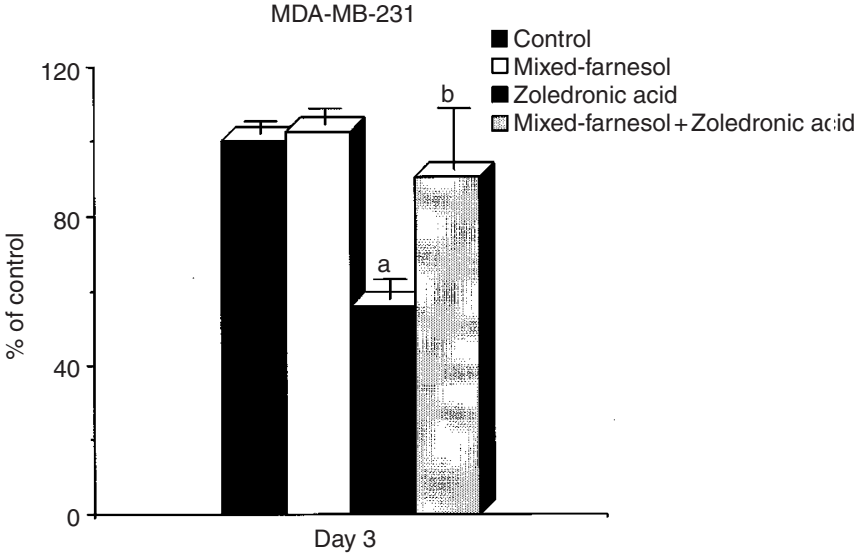

B

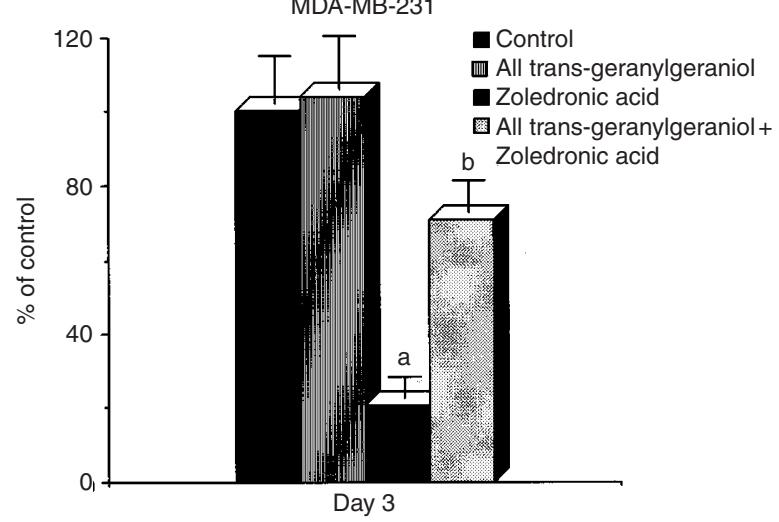

Figure 5 (A) Effects of $\mathrm{FOH}$ (mixed isomers) on ZOL-induced inhibition of cell viability. MDA-MB-23I cells were treated with or without $40 \mu \mathrm{M}$ of $\mathrm{FOH}$ (mixed isomers) $3 \mathrm{~h}$ before addition of $40 \mu \mathrm{M} \mathrm{ZOL}$ for $24 \mathrm{~h}$. Medium was then replaced with fresh medium containing $40 \mu \mathrm{M}$ $\mathrm{FOH}$ (mixed isomers) or vehicle (ethanol) only for a further 3 days. Results are shown as mean \pm s.d. Significance ${ }^{a} P<0.000$ I vs vehicle treated cells (control). b $\mathrm{P}<0.000 \mathrm{l}$ vs $\mathrm{ZOL}$ alone treated cells. Control vs $\mathrm{ZOL}+$ $\mathrm{FOH}$ was not significant $(P=0.86)$. (B) Effects of all trans-GGOH $(40 \mu \mathrm{M})$ on ZOL induced inhibition of cell viability. MDA-MB-23I cells were treated with or without $40 \mu \mathrm{M}$ all trans-GGOH for $3 \mathrm{~h}$ before exposing to $40 \mu \mathrm{M}$ of $\mathrm{ZOL}$ for $24 \mathrm{~h}$. Medium was then replaced with fresh medium containing $40 \mu \mathrm{M}$ all trans-GGOH alone or vehicle only. Results are shown as mean \pm s.d. Significance a $P<0.000$ l vs vehicle treated cells (control). ${ }^{b}$ $P<0.0014$ vs ZOL alone treated cells. Viability of cultures treated with $\mathrm{ZOL}+\mathrm{GGOH}$ was significantly lower than control $(P<0.0 \mathrm{I})$.

induced by a large variety of stimuli (Korsmeyer, 1999). It has been suggested that bcl-2 prevents the release of cytochrome $c$ into the cytosol, thereby inhibiting the activation of caspases (Marzo et al, 1998). An aim of the present study was to clarify the involvement of bcl-2 and cytochrome $c$ release in ZOL mediated caspase activation in breast cancer cells. We have already shown that bcl-2 protein is down-regulated upon treatment of breast cancer cells with N-BPs (Senaratne et al, 2000) and now report that forced expression of bcl-2 in MDA-MB-231 breast cancer cells efficiently inhibits ZOL-induced DNA fragmentation, which is a consequence of caspase activation in breast cancer cells. These results are in agreement with a study carried out on myeloma cells demonstrating that forced expression of bcl-2 is capable of abrogating BP induced apoptosis (Aparicio et al, 1998). We now demonstrate for the first time that treatment of breast cancer cells with ZOL is associated with release of mitochondrial cytochrome $c$ into the cytosol.

Support for the role of caspase activation in N-BP-induced apoptosis in breast cancer cells is provided by demonstration of PARP cleavage (Senaratne et $a l, 2000$ ) as well as abrogation by zVAD-fmk (a broad-spectrum caspase inhibitor) of MCF-7 cell growth inhibition induced by four BPs (zoledronic acid, ibandronate, pamidronate and clodronate, Fromigue et al, 2000). Activation of caspase-3-like proteases is thought to be an irreversible step in the pathway leading to DNA fragmentation in apoptotic cell death (Cohen, 1997). Hiraga et al (2001) have demonstrated that a selective caspase- 3 inhibitor is capable of blocking ibandronate-induced DNA fragmentation in MDA-MB231 breast cancer cells and we have similarly found that caspase3 inhibition significantly protects against ZOL-induced loss of viability in these cells.

Furthermore, in the present study we have presented direct evidence for activation of this cell death protease by ZOL in MDA-MB-231 breast cancer cells by immunoblotting. We and others (Fromigue et al, 2000; Senaratne et al, 2000; Jagdev et al, 2001) have demonstrated that N-BPs are capable of inducing loss of cell viability and DNA fragmentation in MCF-7 cells which are caspase-3 null (Kurokawa et al, 1999). However, our present study illustrates that in MCF-7 cells stably transfected with caspase-3, ZOL is capable of activating this cell-death protease. We suggest that in parental MCF-7 cells, treatment with N-BPs is associated with activation of another caspase, possibly caspase 7 (Puig et al, 2001).

How does treatment of breast cancer cells with N-BPs lead to cytochrome $c$ release and caspase activation? In order to address this question we evaluated the possible role of impaired protein prenylation. Recent pharmacological studies suggest that N-BPs such as pamidronate, alendronate and risedronate act on the cholesterol biosynthetic pathway (Luckman et al, 1998; Shipman et al, 1998). N-BPs such as ZOL have recently been shown to inhibit farnesyl pyrophosphate synthase (van Beek et al, 1999a; Dunford et al, 2001) thus blocking the production of the pyrophosphate intermediates FPP and GGPP. These intermediates are important for post-translational modification of key regulatory proteins. Prenylation of small G proteins such as Rac, Rho and various members of the Rab family occurs through transfer of either one or two 20 carbon geranylgeranyl isoprenoids from GGPP to these proteins (reviewed in Rowinsky, 1999) by the action of geranylgeranyl transferases (GGTases). Another key prenylated protein is Ras, which undergoes farnesylation by the addition of a 15-carbon farnesyl isoprenoid from FPP by the action of farnesyl transferase (FTase). Failure of FPP and GGPP generation by inhibition of FPP synthase would thus be expected to lead to impaired prenylation of these important regulatory proteins.

Ras proteins play pivotal roles in the control of normal and transformed cell growth. While ras mutations are not as common in breast cancer as in some other types of malignancy, the increased activity of growth factor signalling pathways which are mediated via Ras proteins makes targeting Ras action an attractive option in breast cancer treatment. By preventing maturation into its biologically active form, farnesyl transferase inhibitors (FTIs) abolish the membrane localisation (Lerner et al, 1995) and function of Ras (Nagase et al, 1996) and these agents are currently under evaluation in clinical trials in patients with breast cancer (Johnston and Kelland, 2001). We have determined if N-BPs can also prevent Ras processing leading to its cytoplasmic accumulation. In MDAMB-231 and MCF-7 cells, treatment with ZOL for 3 days clearly prevented membrane localisation of Ras as determined by immunoblotting. Therefore our results suggest for the first time that $\mathrm{N}$-BPs inhibit Ras processing and membrane localisation in breast cancer cells in a manner similar to FTIs.

To investigate the role of protein prenylation in N-BP mediated apoptosis in breast cancer cells further, we determined if replace- 
ment of intracellular isoprenoids could rescue breast cancer cells from ZOL-induced apoptosis. In most studies designed to investigate this potential mechanism in osteoclasts and macrophages, the ability of FOH and GGOH to prevent effects of N-BPs have been utilised. These analogues of FPP and GGPP have been reported to display greater membrane permeability and be converted to the respective pyrophosphate forms intracellularly by a salvage pathway (Crick et al, 1997). In osteoclasts, N-BP-induced apoptosis was attenuated by addition of GGOH but not FOH (Fisher et al, 1999; van Beek et al, 1999b). However, in J774 macrophages undergoing N-BP induced apoptosis, addition of either $\mathrm{FOH}$ or GGOH (Benford et al, 1999) inhibited caspase-3 activation and induction of apoptosis. Our present study in breast cancer cells has shown that FOH (mixed isomers) both protects MDA-MB231 cells from ZOL-induced inhibition of cell viability and attenuates ZOL-induced loss of Ras membrane localisation in MCF-7 cells. This suggests that Ras is one important prenylated protein that is altered in activity by N-BP treatment of breast cancer cells. We found that co-treatment with GGOH was less effective than FOH in protecting MDA-MB-231 cells from ZOL-induced apoptosis. This is in contrast to a recent study by Jagdev et al (2001) who reported that co-treatment with GGOH rescued MCF-7 cells from ZOL induced apoptosis whereas $\mathrm{FOH}$ had little effect.

Taken together our present results demonstrate that ZOL induces apoptosis in human breast cancer cells. This apoptosis is associated with release of cytochrome $c$ into the cytosol and subse-

\section{REFERENCES}

Aparicio A, Gardner A, Tu Y, Savage A, Berenson J, Lichtenstein A (1998) In vitro cytoreductive effects on multiple myeloma cells induced by bisphosphonates. Leukemia 12: 220-229

Benford HL, Frith JC, Auriola S, Monkkonen J, Rogers MJ (1999) Farnesol and geranylgeraniol prevent activation of caspases by aminobisphosphonates: biochemical evidence for two distinct pharmacological classes of bisphosphonate drugs. Molec Pharmacol 86: 131-147

Body JJ, Bartl R, Burckhardt P, Delmas PD, Diel IJ, Fleisch H, Kanis JA, Kyle RA, Mundy GR, Paterson AH, Rubens RD (1998) Current use of bisphosphonates in oncology. Clin Oncol 16: 3890-3899

Boissier S, Magnetto S, Frappart L, Cuzin B, Ebetino FH, Delmas PD, Clezardin P (1997) Bisphosphonates inhibit prostate and breast carcinoma cell adhesion to unmineralized and mineralized bone extracellular matrices. Cancer Res 57: 3890-3894

Boissier S, Ferreras M, Peyruchaud O, Magnetto S, Ebetino FH, Colombel M, Delmas P, Delaisse J-M, Clezardin P (2000) Biphosphonates inhibit breast and prostate carcinoma cell invasion, an early event in the formation of bone metastases. Cancer Res 60: 2949-2954

Cohen GM (1997) Caspases, the executioners of apoptosis. Biochem J 15: 326 (Pt 1) $1-16$

Cory AH, Owen TC, Barltrop JA, Cory JG (1991) Use of an aqueous soluble tetrazolium/formazan assay for cell growth assays in culture. Cancer Commun 3: $207-212$

Crick DC, Andres DA, Waechter CJ (1997) Novel salvage pathway utilizing farnesol and geranylgeraniol for protein isoprenylation. Biochem Biophys Res Comm 237: 483-487

Diel IJ, Solomayer E, Costa SD, Gollan C, Goerner R, Wallwiener D, Kaufmann M, Bastert G (1998) Reduction in new metastases in breast cancer with adjuvant clodronate treatment. $N$ Engl J Med 339: 357-363

Duke RC, Cohen JJ (1992) Morphological, biochemical, and flow cytometric assays of apoptosis. In Current protocols in Immunology (Suppl 3) Coligan JE, Kruisbeek AM, Margulies DH, Shevach EM, Strober W (eds) pp 3.17.11-3.17.16 New York: Green/Wiley

Dunford JE, Thompson K, Coxon FP, Luckman SP, Hahn FM, Poulter CD, Ebetino FH, Rogers MJ (2001) Structure-activity relationships for inhibition of farnesyl diphosphate synthase in vitro and inhibition of bone resorption in vivo by nitrogen-containing bisphosphonates. J Pharm Exp Ther 296: $235-242$ quent activation of the caspase cascade. These effects are abrogated by forced expression of bcl-2. Our results implicate a role for protein prenylation and impaired Ras membrane localisation in apoptosis. Further research is likely to provide valuable insights into the role played by prenylated proteins in the initiation of these apoptotic pathways. Currently BPs are used in the treatment of patients who develop bone metastases from carcinoma of the breast. The primary aim here is to reduce the skeletal morbidity such as bone pain, fracture and hypercalcaemia (Hortobagyi et al, 1996; Body et al, 1998). At present, the report by Diel et al (1998) is the only one to demonstrate a survival advantage with the use of clodronate in the adjuvant setting. With the advent of the newer and more potent BPs such as ZOL, the potential to make an impact on progression-free and overall survival may be achieved. Knowledge of the various pathways involved may facilitate additional therapeutic interventions to maximise the effects of BPs.

\section{ACKNOWLEDGEMENTS}

The study was supported in part by the Pathological Research Fund SGHMS. We thank Professor Mike Clemens for his helpful discussion and Professor Alan Porter for providing us with caspase-3 expressing MCF-7 cells.
Fisher JE, Rogers MJ, Halasy JM, Luckman SP, Hughes DE, Masarachia PJ, Wesolowski G, Russell RG, Rodan GA, Reszka AA (1999) Alendronate mechanism of action: geranylgeraniol, an intermediate in the mevalonate pathway, prevents inhibition of osteoclast formation, bone resorption, and kinase activation in vitro. Proc Natl Acad Sci 96: 133-138

Fromigue O, Lagneaux L, Body J (2000) Bisphosphonates induce breast cancer cell death in vitro. J Bone Miner Res 15: 2211-2221

Gilhooly EM, Rose DP (1999) The association between a mutated ras gene and cyclooxygenase-2 expression in human breast cancer cell lines. Int $J$ Oncol 15: $267-270$

Hiraga T, Williams PJ, Mundy GR, Yoneda T (2001) The bisphosphonate ibandronate promotes apoptosis in MDA-MB-231 human breast cancer cells in bone metastases. Cancer Res 61: $4418-4424$

Hortobagyi GN, Theriault RL, Porter L, Blayney D, Lipton A, Sinoff C, Wheeler H, Simeone JF, Seaman J, Knight RD (1996) Efficacy of pamidronate in reducing skeletal complications in patients with breast cancer and lytic bone metastases. N Engl J Med 335: 1785-1791

Jagdev SP, Coleman RE, Shipman CM, Rostami-H A, Croucher PI (2001) The bisphosphonate, zoledronic acid, induces apoptosis of breast cancer cells: evidence for synergy with paclitaxel. Br J Cancer 84: 1126-1134

Johnston SR, Kelland LR (2001) Farnesyl transferase inhibitors-a novel therapy for breast cancer. Endocr Relat Cancer 8: 227-235

Korsmeyer SJ (1999) Bcl-2 gene family and the regulation of programmed cell death. Cancer Res 59: 1693s-1700s

Kurokawa H, Nishio K, Fukumoto H, Tomonari A, Suzuki T, Saijo N (1999) Alteration of caspase-3 (CPP32/Yama/apopain) in wild-type MCF-7, breast cancer cells. Oncol Rep 6: 33-37

Lerner EC, Qian Y, Blaskovich MA, Fossum RD, Vogt A, Sun J, Cox AD, Der, CJ, Hamilton AD, Sebti SA (1995) Ras CAAX peptidomimetic FTI-277 selectively blocks oncogenic Ras signaling by inducing cytoplasmic accumulation of Ras-Raf complexes. J Biol Chem 270: 26802-26806

Li P, Nijhawan D, Budihardjo I, Srinivasula SM, Ahmad M, Alnemri ES, Wang X (1997) Cytochrome c and dATP-dependent formation of Apaf1/caspase-9 complex initiates anapoptotic protease cascade. Cell 91: $479-489$ 
Luckman SP, Hughes DE, Coxon FP, Graham R, Russell G, Rogers MJ (1998) Nitrogen-containing bisphosphonates inhibit the mevalonate pathway and prevent post-translational prenylation of GTP-binding proteins, including Ras. J Bone Miner Res 13: $581-589$

Marzo I, Susin SA, Petit PX, Ravagnan L, Brenner C, Larochtte N, Zamzmi N, Kroemer G (1998) Caspases disrupt mitochondrial membrane barrier function. FEBS Lett 427: 198-202

Mumby SM, Casey PJ, Gilman AG, Gutowski S, Sternweis PC (1990) G protein? subunits contain a 20-carbon isoprenoid. Proc Natl Acad Sci 87: $5873-5877$

Nagase T, Kawata S, Tamura S, Matsuda Y, Inui Y, Yamasaky E, Ishiguro H, Ito T, Matsuzawa Y (1996) Inhibition of cell growth of human hepatoma cell line (Hep G2) by a farnesyl protein transferase inhibitor: a preferential suppression of Ras farnesylation. Int J Cancer 65: 620-626

Puig B, Tortosa A, Ferrer I (2001) Cleaved caspase-3, caspase-7 and poly (ADP-ribose) polymerase are complementarily but differentially expressed in human medulloblastomas. Neurosci Lett 306: $85-88$

Rowinsky EK, Windle JJ, Von Hoff DD (1999) Ras protein farnesyltransferase: a strategic target for anticancer therapeutic development. J Clin Oncology 17: $3631-3652$

Ryzen E, Martodam R, Troxell M, Benson A, Paterson A, Shepard K, Hicks R (1985) Intravenous etidronate in the management of malignant hypercalcaemia. Arch Intern Med 145: 449-452

Sasaki A, Boyse BF, Story B, Wright KR, Chapman M, Boyce R, Mundy GR, Yoneda T (1995) Bisphosphonate risedronate reduces metastatic human breast cancer burden in bone in nude mice. Cancer Res 55: 3551 - 3557

Senaratne SG, Pirianov G, Mansi JL, Arnett TR, Colston KW (2000) Bisphosphonates induce apoptosis in human breast cancer cell lines. $\mathrm{Br} \mathrm{J}$ Cancer 82: $1459-1468$
Shipman CM, Croucher PL, Russell RGG, Helfrich MH, Rogers MJ (1998) The bisphosphonate incadronate (YM175) causes apoptosis of human myeloma cells in vitro by inhibiting the mevalonate pathway. Cancer Res 58: $5294-5297$

Slee EA, Keogh SA, Martin SJ (2000) Cleavage of BID during cytotoxic drug and UV radiation-induced apoptosis occurs downstream of the point of Bcl-2 action and is catalysed by caspase-3: a potential feedback loop for amplification of apoptosis-associated mitochondrial cytochrome c release. Cell Death Differ 6: 556-655

van Beek E, Pieterman E, Cohen L, Lowik C, Papapoulos S (1999a) Farnesyl pyrophosphate synthase is the molecular target of nitrogern containing bisphosphonates. Biochem Biophys Res Comm 264: 108-111

van Beek E, Lowik C, van der Plum G, Papapoulos S (1999b) The role of geranylgeranylation in bone formation and its suppression by bisphosphonates in fetal bone explants in vitro: a clue to the mechanism of action of nitrogen-containing bisphosphonates. J Bone Min Res 14: 722-729

van der Pluijm G, Vloedgraven H, van Beek E, van der Wee-Pals L, Lowik C, Papapoulos S (1996) Bisphosphonates inhibit the adhesion of breast cancer cells to bone matrices in vitro. J Clin Invest 98: 698-704

Wingen F, Eichmann T, Manegold C, Krempien B (1986) Effects of new bisphosphonates acids on tumor-induced bone destruction in the rat. $J$ Cancer Res Clin Oncol 111: 35-41

Yoneda T, Michigami T, Yi B, Williams PJ, Niewolna M, Hiraga T (2000) Actions of bisphosphonate on bone metastasis in animal models of breast cancer carcinoma. Cancer 88(12 suppl): 2979-2988

Zou H, Henzel WJ, Liu X, Lutschg A, Wang X (1997) Apaf-1, a human protein homologous to $C$. elegance CED-4, participates in cytochrome cdependent activation of caspase-3. Cell 90: 405-413 